\title{
Hazards Identification Model for Rail Rapid Transit Accidents
}

Lung-Chuang Wang

Associate professor, Department of Civil Engineering, National Taipei University of Technology, Taipei, Taiwan, R.O.C., lcwang@ntut.edu.tw

Follow this and additional works at: https://jmstt.ntou.edu.tw/journal

Part of the Civil and Environmental Engineering Commons

\section{Recommended Citation}

Wang, Lung-Chuang (2004) "Hazards Identification Model for Rail Rapid Transit Accidents," Journal of Marine Science and Technology. Vol. 12: Iss. 2, Article 2.

DOI: $10.51400 / 2709-6998.2223$

Available at: https://jmstt.ntou.edu.tw/journal/vol12/iss2/2

This Research Article is brought to you for free and open access by Journal of Marine Science and Technology. It has been accepted for inclusion in Journal of Marine Science and Technology by an authorized editor of Journal of Marine Science and Technology. 


\title{
HAZARDS IDENTIFICATION MODEL FOR RAIL RAPID TRANSIT ACCIDENTS
}

\author{
Lung-Chuang Wang*
}

Key words: rail rapid transit, accidents analysis, hazard identification, accident causation.

\begin{abstract}
In comparison with the other transportation modes, rail rapid transit already enjoys a higher degree of safety as it is designed with the exclusive right of way and the automatic train control and monitoring systems. Nevertheless, rail rapid transit systems are not free from serious accidents, which often led to human injuries and facility damages. The planning of accident prevention and emergency measures, therefore, are still important issues of the rail rapid transit operations. The model presented in this study analyses the process of hazard identification in two stages, which clearly indicate the factors of the inherent and direct hazard and the weaknesses in the response system. The study uses the fire accident took place in the Mucha Line of Taipei Rapid Transit System in 1993 as an example to illustrate the hazard identification model by pointing out the cause of the incident and the weakness in the emergency systems.
\end{abstract}

\section{INTRODUCTION}

Rail rapid transits have already become an indispensable means of public transportation for modern cities. To date, there are hundreds of rail rapid transit systems located in different parts of the world. While these systems have provided solutions for a fast, comfortable, reliable, and convenient means of transportation for travels in the urban areas, the rail rapid transit is also expected to provide comprehensive measures to ensure the operation safety. In comparison with the other transportation modes, rail rapid transit already enjoys a higher degree of safety as it is designed with the exclusive right of way and the automatic train control and monitoring systems. Still, rail rapid transit systems are not free from serious accidents, which often lead to human injuries and facility damages and may result in secondary disasters (e.g., heavy injuries may be in-

Paper Submitted 01/27/04, Accepted 03/02/04. Author for Correspondence: Lung-Chuang Wang. E-mail: lcwang@ntut.edu.tw.

*Associate professor, Department of Civil Engineering, National Taipei University of Technology, Taipei, Taiwan, R.O.C. curred by electrical shocks in the confusion of evacuation). According to the statistics from FTA [4] (1993, 1994, 1995), the heavy rail transit suffered a fatality rate of 0.78 per hundred million passengermiles for patrons and non-patrons fatalities.occurring often involve some difficult issues, e.g., the control of operators and passengers and the constraints of the facility and the local environment. Perhaps, it is inevitable that "mishandling are prone to occur whenever manual operation is involved; failures are inevitable whenever machines are employed." Many factors may leads to accidents. If the factors that might resulting in accidents can be identified in advance, some safety process will react to and the loose and damages maybe reduced or eliminated. Therefore, the chief objective of this study is designing methods to identify the hazards of the rail rapid transit accidents. The rail rapid transit mentioned in this study includes the heavy and light rail rapid transits, which have the exclusive right of way, grade separation and the automatic train control and monitoring systems. The definition of "accident" could be termed as unpredictable and unexpected, but in this study, the so-called "accidents" have the causes readily identifiable; only the precise moment when their effects will be noticed is unknown. The definition of hazard is "the source of energy and the physiological and behavioral factors which, when uncontrolled, lead to harmful occurrences." [5]

Hazard identification has been an important issue in occupational safety and the chemical process industries; there are several hazard identification techniques, such as What-if, Checklist, What-if/ Checklist, Hazard and operability study (HAZOP), Failure mode and effects analysis, and Fault tree analysis [13]. On the other hand, hazard identification is closely related with the risk assessment. A risk assessment model described by the National Research Council (NRC) of the National Academy of Sciences [10] has been widely used by several government agencies of the United States, including the EPA, for assessing the risk of cancer and other health risks that result from exposure to chemicals. According to this model, risk assess- 
ment consists of "hazard identification, dose-response assessment, exposure assessment, and risk characterization." The NRC report describes hazard identification as a major undertaking that produces a qualitative determination of whether exposure to a hazardous agent can cause adverse effects. This includes determining cause and effect, weighing the available evidence, and characterizing the nature and strength of the evidence of causation. Differently, Covello and Merkhofer (1993) proposed another model of risk assessment, which regards hazard identification as an altogether separate process that is necessarily conducted prior to risk assessment. They think that treating hazard identification as merely one component of risk assessment underplays its importance. Thus in their model, they define the qualitative process of hazard identification as a distinct process that is on a par with and of equal importance to the quantitative process of risk assessment.

Clearly, this study focuses on such a qualitative approach to identify these hazardous factors of rapid transit. The results might be a starting point for further quantitative risk assessment, or used to develop corrective and precautionary measures for some proved damages of accidents. Accordingly, a case study of the fire accidents happened in the Taipei rapid transit system follows this hazards identification model to illustrate the causes of the accidents and to verify the application of this model.

In the following chapters, the study aims to develop a hazard identification model by reviewing the theory on accident analysis and the rail rapid transit safety features. The hazard identification model con- sists of two parts: the cause-effect chart of hazards induced by three elements (human, system and environment) and the two-stage analysis. Finally, the fire accident happened at the Mucha Line of Taipei Rapid Transit is used as the example to validate the model.

\section{RAIL RAPID TRANSIT HAZARD IDENTIFICATION MODEL}

Given the information of many transit accidents in the past, the accident types and causes may be induced like in the Table 1. However, the real hazards that cause the accident and the relation between them are not easy to figure out intuitively. Therefore, this study proposes a rail rapid transit hazard identification model to facilitate the analysis. This model first establishes the causeeffect charts of hazardous factors that lead to unsafe conditions and then a two-stage analysis is adapted to identify the hazards of the respective incidents or accidents.

\section{Elements of hazards identification}

Generally, rail rapid transit hazards occur because of three elements: (1) Human: operators and passengers; (2) System: material, equipment, tools, and safety facility; (3) Environment: temperature, humidity, ventilation, lights, and noises (natural environment and artificial environment) in the working place. These three elements as contain danger, and may change as the time passes by if there is no proper control and management; therefore, practicing to control and elimi-

Table 1. List of major transit accident types and possible causes

\begin{tabular}{ll}
\hline \multicolumn{1}{c}{ Types } & \multicolumn{1}{c}{ Possible Causes } \\
\hline Fire & $\begin{array}{c}\text { Arson, failure of electrical equipment, brakes operation, storage of inflammable } \\
\text { material, derailing, the strike of lightening } \\
\text { Poor design or failure of the drainage system } \\
\text { Flood }\end{array}$ \\
$\begin{array}{l}\text { (1) Violation of stop signs by the driver (intrusion). (2) Failure of the ATC system. } \\
\text { (3) Signal errors. (4) Breakdown or mishandling of the split switch. }\end{array}$ \\
$\begin{array}{ll}\text { (1) Incomplete release of hand brake. (2) Inadequate geometric design. (3) Excessive rocking } \\
\text { of the trains (4) Speeding at the turn. (5) Damage of the bearing and wheel. (6) Rail deformation. } \\
\text { Jammed by the door or the uncontrolled opening of the door. }\end{array}$ \\
$\begin{array}{l}\text { Door Accident } \\
\text { Breakdowns of power } \\
\text { supply system }\end{array}$ & $\begin{array}{c}\text { Failure of the power supply or emergency power supply facilities, overload, } \\
\text { mishandling, or struck by lightening. } \\
\text { Antrusion }\end{array}$ \\
$\begin{array}{l}\text { Animals or people could be found intruding the track on the level ground or the station. } \\
\text { Scraped by the train } \\
\text { Natural Disaster }\end{array}$ & $\begin{array}{l}\text { Inadequate design of the platform or station } \\
\text { Mindless passenger or lack of proper signs on the platform } \\
\text { Others }\end{array}$ \\
\hline
\end{tabular}

* Induced from NTSB (1972-1981); San Francisco BART (1985-1988); and Wang (1993). 
nate the factors of hazards on these elements is the basis of preventing adverse consequences.

If we analyze specifically about the causes that lead to system and environmental unsafe conditions, we find that almost all defects come from human errors in design, installation, operation, treatment, and uses. Hollnagel (1993) reveal that the estimated involvement of human error in the breakdown of hazardous technologies increased fourfold between the 1960s and the 1990s, from minima of around $20 \%$ to maxima of more than $80 \%$. Even the defects in natural environment can be reduced or prevented by pre-alarm system and preventive measures. Therefor, almost all unsafe conditions could be regarded as human errors or faults. If we can eliminate the above-mentioned unsafe elements to control human behavior, both unsafe behavior and unsafe conditions will not happen again. After a series of researches on accident causation model, Reason (1995) proposed a system approach to analysis organizational error, and the main focus is upon the human contribution within these broader systems domains. However, human behaviors are extremely complicated and are affected by personal characteristics and environmental conditions. As the hazards in rail rapid transit accident are concerned, the major factors that affect human behaviors are suggested as in Fig. 1.

Though the human error could be regarded as the major cause of rail rapid transit accident, the human behaviors also result from the transit equipment, facilities, and the other environmental factors. Even the personal desire, emotion and personality are nurtured in society. These internal and external conditions interact on each other to form human conscious and subcon-

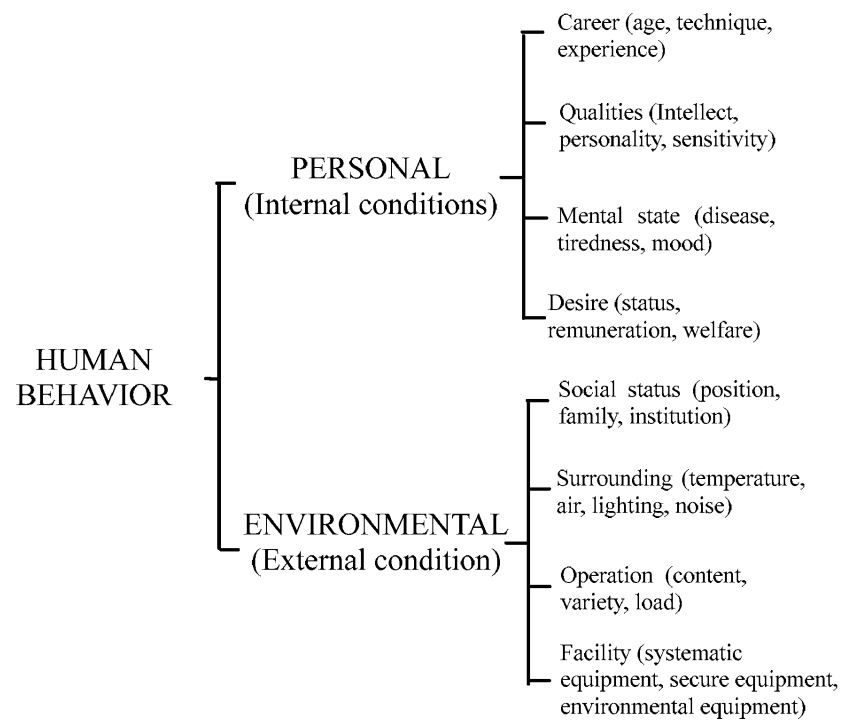

Fig. 1. Main factors affecting human behavior in rail rapid transit hazards. scious actions, which will be complicated and difficult to understand in a lopsided view. That is why all the factors must be considered altogether; otherwise, it would be difficult to find out real hazards and prevent unsafe behavior from happening recurrently.

\section{Establishing the cause-effect relationship}

In this section, contributing factors for the cause of rail rapid transit accidents are proposed and classified as human induced, system induced, or environmentally induced. Most of the accidents, however, are not caused by a single factor, there are usually a cluster of factors interacted with each other. As the three groups of main factors bear influences on one another, it is important to devise a scheme that can manage the consequence of the three elements and recognize hazardous conditions to ensure the operation safety. The following Fig. 2 to Fig. 4 are the fishbone charts that this study uses to provide cause-effect relationship of how these factors lead to hazards. In these figures, the large-boned branches are the latent causes and the sub-branches are the active causes, which both contribute to one of the three main factors (in the backbone of the fish) and will finally lead to unsafe behaviors or unsafe conditions (in the fish head). Note that the active causes in the sub-branches are obviously not comprehensive or restricted within those factors for all situations. Different cases or even different transit organizations should fine-tune these active and latent factors and bring up their own hazardous factors when applying these figures.

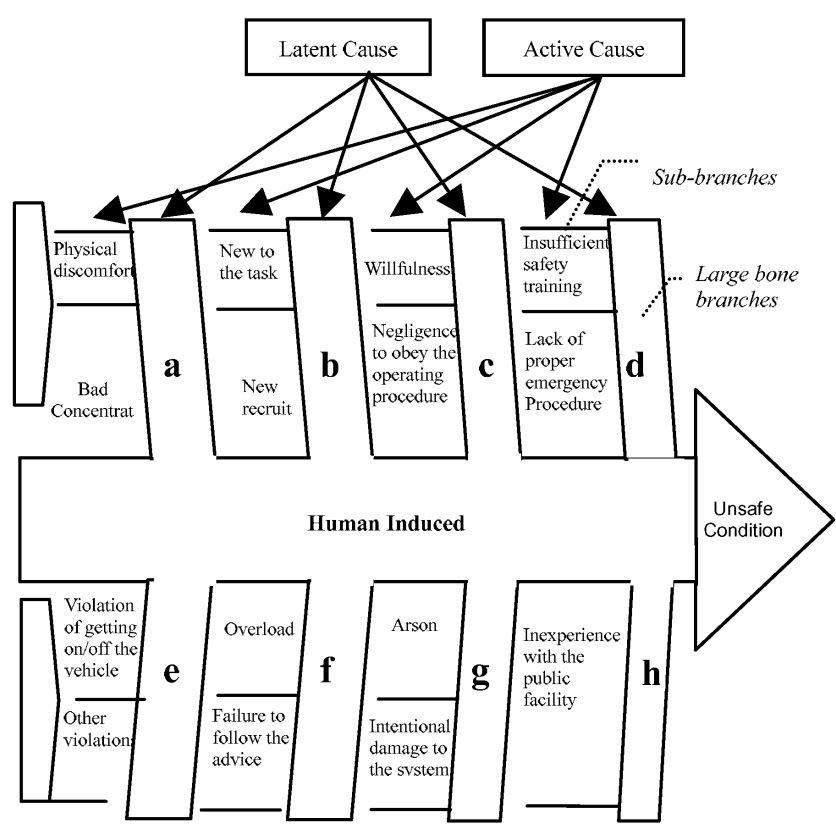

Fig. 2. Human induced hazards in rail rapid transit systems. 


\section{Human induced factors}

Human induced accidents could be attributed to either the operators or the passengers, but the operators are more likely to be the media of accidents. Factors leading to operator induced accidents include (a) Physical and mental conditions. Fatigue or other illness may cause the operators to perform erroneous procedure. Unstable mental state could also influence normal operation; (b) Immature operating skills; (c) Failure to follow the operation procedure; (d) Lack of safety knowledge and awareness. Factors leading to the passengerinduced accidents are (e) Illegal actions; (f) Mindless of the dangers; (g) Deliberate act; (h) Deficient in common sense. The above factors are the main latent causes and indicated at the large-boned branches of Fig. 2. One or two possible active causes are proposed and followed in each sub-branch.

\section{System induced factors}

The rail rapid transit system is composed of equipment (rolling stock, signaling, and power supply) and station facilities (platform, track, and others). The factors leading to the system induced accidents include (a) Inadequate selection of equipment. Examples include: capacity of the equipment could not satisfy the functional demand, the equipment is below the safety standard; and equipment cannot adapt to the unique environmental set up. (b) Inadequate installation of equipment; (c) Inadequate maintenance of equipment; (d) Equipment exceeding the design life cycle. (e) Inadequate application of equipment; (f) Inadequate design of equipment. These factors are indicated as in the Fig. 3.

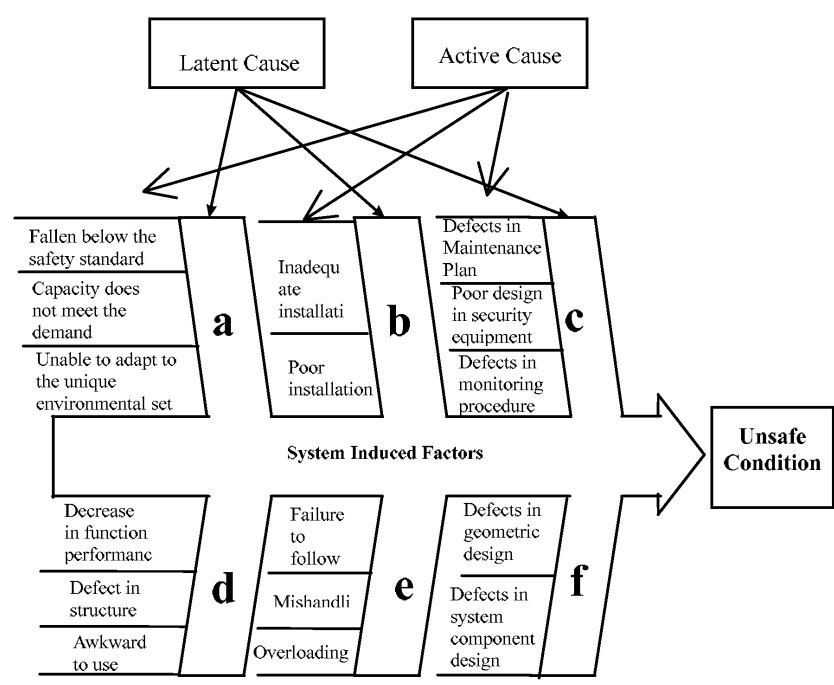

Fig. 3. System induced hazards in rail rapid transit systems.

\section{Environmentally induced factors}

This aspect can be further divided into the natural environment and the working environment. 1. Natural environment. Such as earthquakes, lightening, flood, typhoons, or heat waves may affect the transit operation. 2. Working environment. Working environment can be further divided into two parts, the software and the hardware. Software includes organizational structure, management efficiency, remuneration, and labor relations. Hardware refers to the lighting, the ventilation, temperature, and humidity of the place at work. An efficient and integral operating organization is not only to the organization itself, but it also has direct influence on the control and prevention of the human-induced and system-induced hazards.

\section{Two-stage analysis}

The process of rail rapid transit hazard identification can be described in two stages. This is depicted as in Fig. 5.

\section{A. The first stage}

Three groups of potential hazardous (humaninduced, system induced, and environmentally induced) factors would cause the system unsafe conditions, while they might not affect the normal operation immediately. Under such a situation, the specific unsafe conditions or behaviors can trace back and identify the inherent hazards by applying the fishbone charts of human, system

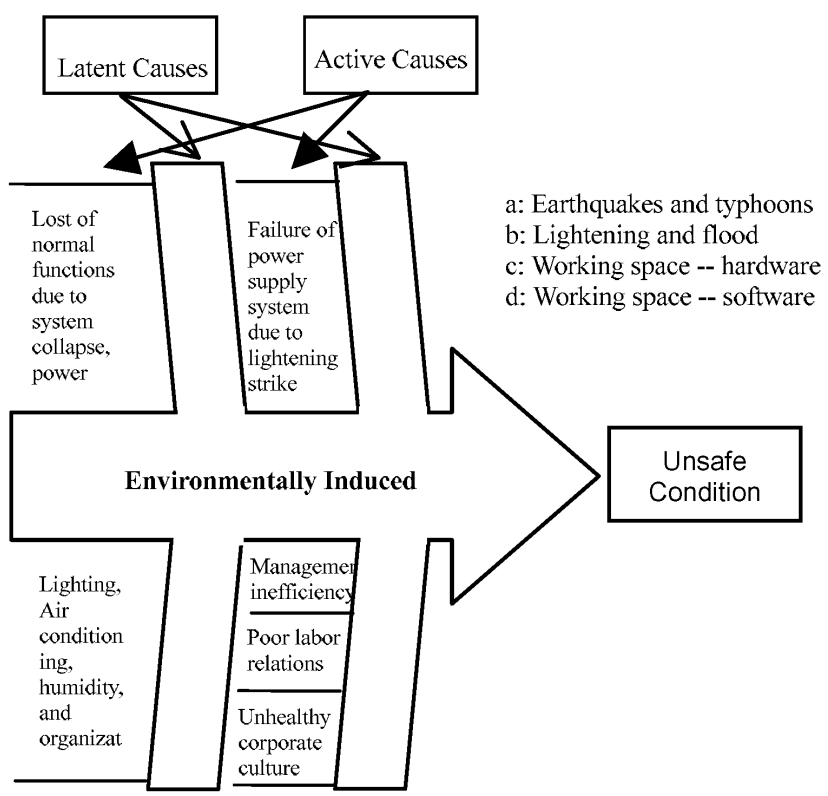

Fig. 4. Environmentally induced hazards in rail rapid transit systems. 
or environment induced factors. In this case, most of the hazards can be eliminated under a perfect management system, for example: an accurate routine check system, the alertness of the operators, a good auditing system, and a strict quality and safety control system.

\section{B. The Second Stage}

Necessary defenses or barriers are the last shift use to keep the unsafe situations from adverse consequences. If the unsafe situations keep on remaining in the system, the barriers themselves are identified as the source of direct hazards in the second stage. As far as the rail rapid transit is concerned, all the safety design is targeted in removing the hazardous factors. Whereas the potential hazards are not eliminated in the first stage, the automatic train operation control and monitoring system will come into play. The Automatic Train Supervision (ATS) and Automatic Train Protection (ATP) should detect any abnormalities in the system and send the messages to the control center for correction, or to the driver to pull on the emergency brake. If the system involves no manual operation, i.e., a "driverless" system, the rate of removing errors through the automatic train control and monitoring system should be $100 \%$. Once the unsafe conditions keep on exposing, the hazards in the second stage will be identified by the factors that the automatic train control and monitoring system fail to respond with safety measures and stop the exposure of hazardous elements.

All the elements of hazards, i.e., the human, system and environment, are the foundation for the analysis. At first stage, the inherent hazards are identified by the related factors of these three elements for different incidents. Though the direct hazards are identified specifically in relation to the automatic train control and monitoring system at the second stage, the defects of such defending systems still result from factors belong to human, system or environment induced.

The two-stage analysis provides the first step to detect the causes of rail rapid transit accidents and composes the major part of the hazard identification model. To explain how to use it, we will demonstrate the process by the real case in next section.

\section{CASE STUDY}

Mucha line is the first completed and the only automatic guided light rail rapid transit line in Taipei. Along the 10.9-kilometer route, there are 12 stations and a Mucha maintenance depot. The construction date started in 1988. Forecasted substantial completion date was originally August 2, 1993, which deferred to June 1994 for two serious fire accidents. Finally, the com- mercial operation starts at March 1996. Five serious accidents, which suspending trains operation over one hour, were recorded for the first year of commissioning, which is way over the acceptable standard $(0$ accident per million $\mathrm{km}$ )

Mucha line uses the MATRA VAL 256 system, which is originally designed as a "driverless", twocoach (one married-pair) system, with one coach equipped with ATC system. The Department of Rapid Transit Systems (DRTS) of Taipei city government, however, demand the system to change to a two married-pair system to provide better service capacity and operation flexibility with the condition that the new design should include operation safety guarantee, facility integration, and protection of passenger emergency evacuation. The VAL automatic control system in each married-pair is designed with the fail-safe principle and consisted of On-Board Control Unit (OBCU, including on-board ATP, ATO, and ATS), Fixed Automatic Train Control (Fixed ATC), Dwell Operation Control Unit (DOCU), Operation Control Center (OCC), and Safety Frequency and High Voltage Logic [8]. After four month of the first fire incident, the second fire incident happened at about five o'clock in the morning of September 24, 1993, while the two married-pair is driving back to maintenance depot under automatic train operation. The passer-by heard the explosion and saw the smoky train. The OCC did not aware of the situation until the witness informed the fire department. Though the OCC broke the circuit immediately, the train was burned in great fire that is higher than the roof of the train and clearly watched by the citizenry through the morning TV news. This event became the headlines and shocked the audience.

According to the press release of the accident report submitted by MATRA for this event (quoted from

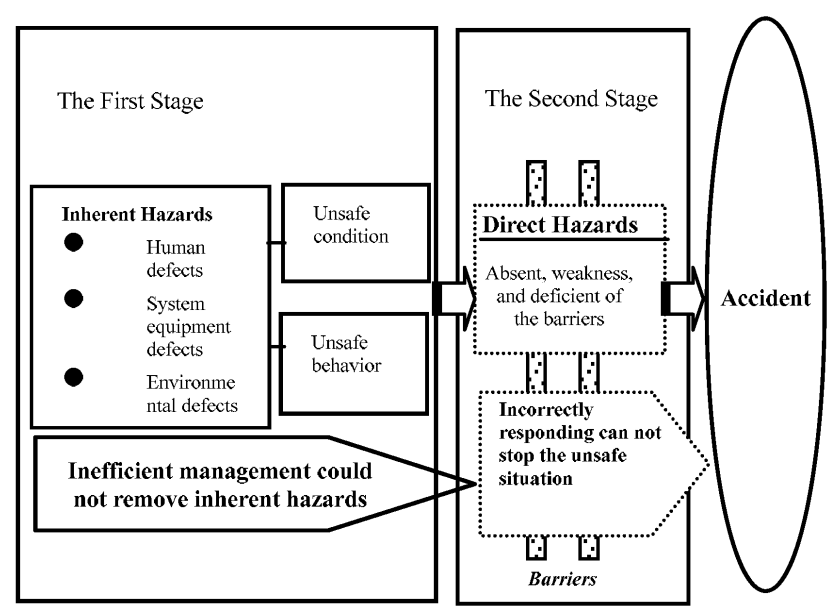

Fig. 5. Two-stage analysis for the identification of hazards in the rail rapid transit. 
the news reported by China Times, October 14, 1993): "The accident was induced by the failure of Traction Safety Rank (TSR) in the third coach of the two married-couple. Because the brake system was malfunctioned, it could not transmit the correct messages to the brake control system, which meant the automatic control system could not inform the other coaches to brake. A coach with the jammed brake being dragged forward by the other three coaches in motion was the cause of the accident." The failures of the Traction Safety Rank and the brake system are unsafe conditions that are result from several factors of hazard. Through the application of hazard identification model presented in last section, the consequence and factors of hazard within this accident are analyzed as follows and depicted as in Fig. 6.

\section{The First Stage}

The unsafe conditions, such as the breakdown of the Traction Safety Rank and the brake system, are classified as system failure - an inherent cause of accident. These hazards induced by system factors could be identified as "Inadequate design and maintenance of equipment" and "Inadequate selection of equipment", which are indicated as the rightest branch in Fig. 7. Another unsafe condition that the OCC fail to be aware of the incident immediately is the total effect of the three elements. The operation staff explained they received too many false messages at that time, so they turn off the alarm bell. This could be regarded as the "lack of safety knowledge and awareness". There might be insufficient safety training for the staff and the emergency procedure is defective. Furthermore, the corporate culture in the operation authority is not aware enough of the importance of safety. 2. The Second Stage After the brake was jammed, the train still ran for an hour and a half (about $2 \mathrm{~km}$ ) before the wheel was

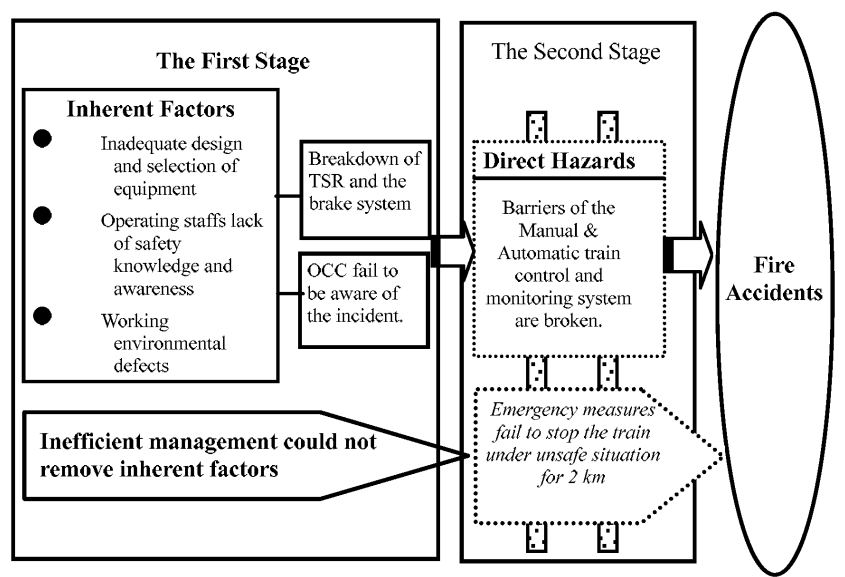

Fig. 6. Two-stage analysis for hazard identification in Mucha lin. caught in fire. The fire accident was created after this stage, and the factors of hazard that broke the barrier are described in the following sections and indicated in Fig. 8 .

\section{A. ATP did not detect any brake failure}

No message was sent to the control center and no emergency measure was taken to correct the situation, hence, the unsafe situation keep on remaining. There are three possible factors accounting for the ATP's failure to detect abnormalities: (a) There was a design defect in ATP; (b) There was a material or manufacturing defect, or (c) ATP was unable to function due to high temperature, magnetic or electric wave interference.

\section{B. ATP had detected brake failure}

Message was transmitted to the control center, but the response of the operator at the control center still fail to stop the exposure of hazards.

1. The operator at the control center made a wrong judgment and did not respond by pulling the brake after receiving the message from ATP. Two contradicting forces could be at work at this time. The operator is giving the command through ATO to allow the train to go forward, while the fail-safe features in ATP is pulling the train to come to a complete stop, hence the safe barrier was broken by the error responding of the operator.

2. The operator responded by pulling the mergency brake, but the system was unable to respond due to the

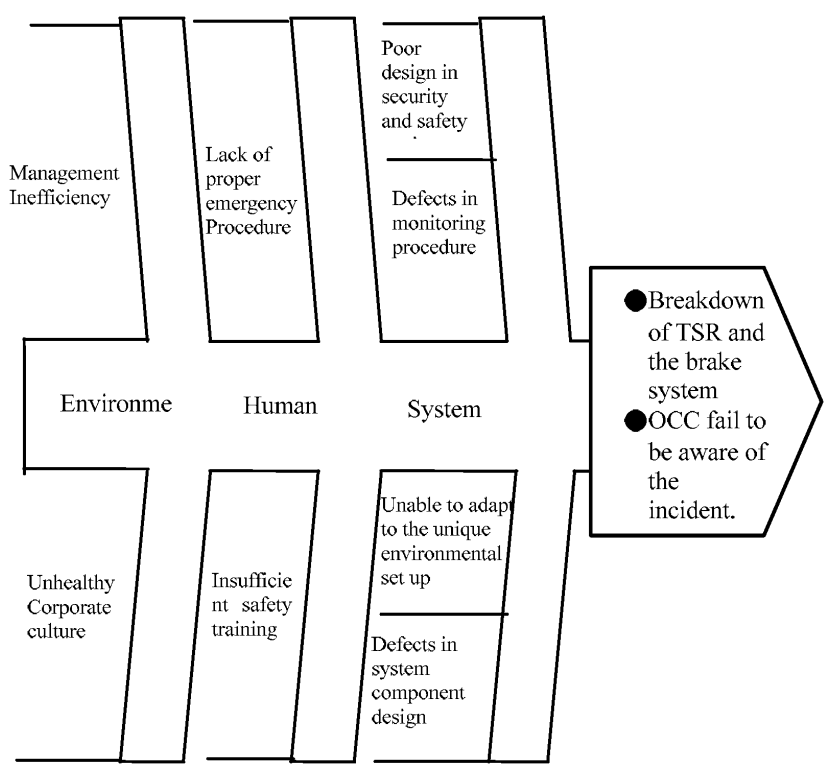

Fig. 7. Hazards identified in the first stage analysis PERSONAL (Internal conditions). 
defect integrating the systems between the two married-pair, i.e., one married pair was braking and the other was running forward, hence the deficient of the communication between the two married pair would be the direct hazards in this stage.

The above analysis was verified in the report [2] that the cause of the September 24, 1993 fire accident was the defect in the design of connecting the married pair. After ATP detected TSR failure in one married pair, it immediately pulled the emergency brake for that system. However, the ATP located in the other married pair did not pick up the messages and carried on driving which led to the wearing of tires. After the train was dragged on for $2 \mathrm{~km}$, it eventually broke out in fire. This is the same as analyzed in the above: the defect integrating the systems between the two married-pair.

In this evaluation report, MATRA proposed seven corrections as the following to improve the safety of the trains and to keep the fire accident from happening again.

1. Install a General Brake Pressure Control Unit that operated by the OBCU.

2. Limit the brake power output during the movement.

3. Enhance the OBCU to automatically verify the output information of the TSR, and the consistence between this information of TSR and the requests from OBCU.

4. Cutoff Traction order in case of Permanent Break Failure (PBF).

5. Add the signal of PBF on the panel of OCC to help the operator making proper decision.

6. Between the brake disk and the rubber tire, add a heat insulation pad that has installed a heat detector on it.

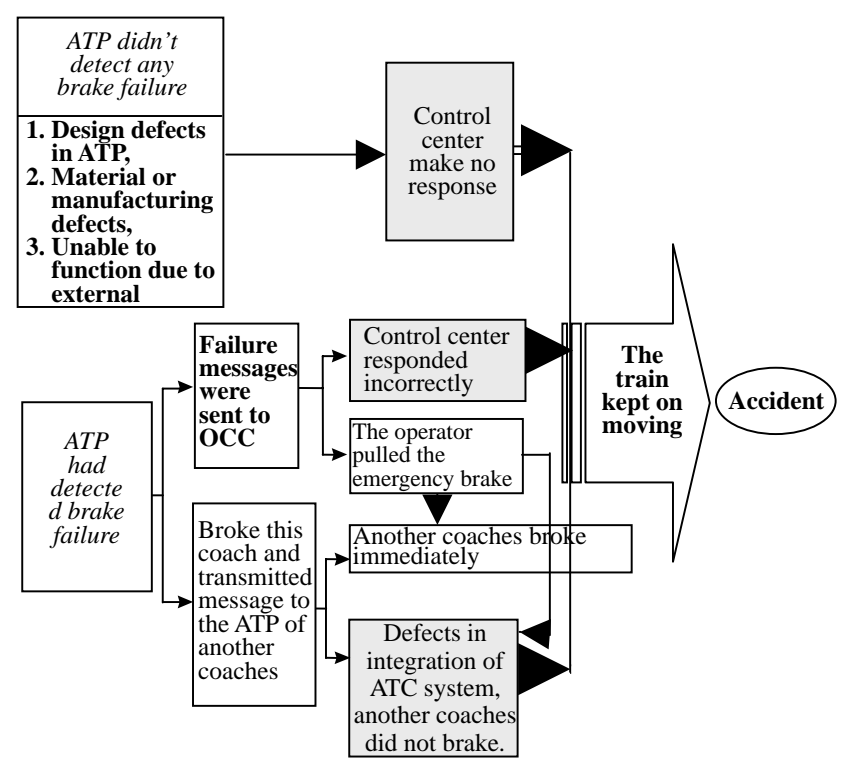

Fig. 8. Consequence diagram for hazards dentification in the second stage analysis.
7. Add a "Coasting Mode" at the time that the coach is starting off to verify the function of PBF detector.

After such improvements, the failure of brakes in any wheel will be passed immediately to the OBCU and the highest control center to switch off the motor. In case of this circuit fails to cut off the traction immediately, the braked wheel will keep on rotating because the torque between the wheel and the dry road surface is larger than that of the brake disk. MATRA says that the new installed heat insulation pad and heat detector on it will send out a warning and switch off the motor emergently when the detected temperature is higher than $110^{\circ} \mathrm{C}$. If the wheels are locked and dragged instead of rotating in the wet road surface, the representative of the Michelin tire company says that the tires will not catch fire but will be worn into puncture. The inspection committee of the city government had recorded and verified these seven corrections in the final reports. So far the Mucha line has been operating commercially for five years (1996-2001). The other three mass transit lines (steel wheel, high capacity) also start to serve during these years. The fire accidents never happen again and the amount of serious accidents is decreasing from 10 times a year in 1997 to 4 times a year in 1999. (According to the statistics data in the web site of Taipei Rapid Transit Company, TRTC: http:// www.trtc.com.tw)

In addition to the above improvements of the brake system, the inspection committee is also devoted on four parts: construction, mechanics and electronic equipment, system integration, and operation management. The committee made comments on the improper corporate culture of transit authority (DRTS and TRTC) and the inadequate emergency procedure. However, these two comments are only parts of those observations that this study has interpreted in the Fig. 7, and there are another two groups of hazards identified from environment and human perspectives. For example, the publicly owned TRTC has been criticized for inefficient management by the citizen and is demanded to become a private company.

\section{DISCUSSION AND CONCLUSION}

The hazards identified in rail rapid transit are different with other transportation modes for two reasons. First, the rail rapid transit is operating under a highly isolated and controlled environment, so the effect of external factors has been reduced considerably. Under the circumstance, the designing and management of the system are the major source of hazards and play critical roles for safety. Second, the rail rapid transit safety features enable the automatic monitoring systems to eliminate the exposure of hazards immediately once the 
hazards are identified. While the hazards keep on exposing, the automatic monitoring system itself must be defective and could be regarded as another factors of hazards.

Owing to such differences, the model presented in this study analyses the process of hazard identification in stages, which clearly indicates the factors of the hazard and the weaknesses in the response system. In the investigation of rail rapid transit accidents, the most easily identified causes are usually related to the equipment or facility failure, such as short circuit, brake jam or erroneous signal. The model proposed by this study however, helps to identify all the hidden and the direct causes of the disaster. The two-stage analysis considering the inherent hazards in the first stage and the direct hazards in the second stage proposes a clear structure to go through the analyzing process and provides more information to the safety planner. When applying to accident causal analysis, the identification of hazards is not concluded with equipment causes, but include human and environment factors at the same time.

When the rail rapid transit accident has happened, the passive strategy derived from this hazard identification model is to recognize the defects in the analyzed system to formulate safety recommendations to improve transportation safety and stop the recurrence. The active or constructive plan of safety management is to control and eliminate the identified inherent hazards by farther improved managerial measures to prevent the accident from occurrence. Finally, what can be done after the identification of hazards? "It seems clear that the pursuit of safety must be pointed toward the identification of hazards, determination of their significance, evaluation of the available correctives, and selection of the optimal remedies. When this path is followed, it ends with the control of unwanted events at an irreducible minimum" [5]. This is the practical view of accident prevention and the application of the model presented in this study can be the basis for further implementation for the transit authority. The analysts of risk assessment can acquire this model to develop quantitative method for analyzing the rail rapid transit accidents. Since the rail rapid transit is one of the public transportation modes, researchers might consider collecting the factors of hazards for other public modes, like aviation and bus transit or other rail modes and should benefit from the ideas presented in this paper.

\section{REFERENCES}

1. Covello, V.T. and Merkhofer, M.W., Risk Assessment Methods: Approaches for Assessing Health and Environmental Risks, Plenum Press, New York (1993).

2. Department of Rapid Transit Systems, Taipei Rapid Transit Red Book-Mucha Line Evaluation Report, Taipei City Government, Taiwan, R.O.C. (1995).

3. Florio, A.E., Alles, W.F., and Stafford, G.T., Safety Education, 4th edition, McGraw-Hill, New York (1979).

4. FTA (Federal Transit Administration), National Transit Database, U.S. Department of Transportation, Washington, D.C. (1993-1995).

5. Grimaldi, J.V. and Simonds, R.H., Safety Management., 5th edition, Richard D. Irwin, Inc., Boston, MA (1989).

6. Heinrich, H.W. and Granniss, E.R., Industrial Accident Prevention: A Scientific Approach, 4th edition, McGrawHill, New York (1959).

7. Hollnagel, E., Human Reliability Analysis: Context and Control. Academic, London (1993).

8. Hwang, C.Y., "VAL System Controlling Architecture," Rapid-Transit Technol., (in Chinese) Vol. 4, pp. 4-13 (1991).

9. Keefer, W.D., "Circumstances Surrounding Accidents," Industrial Safety, Blake, R.P. (Ed.), 2nd edition, PrenticeHall, Inc., New Jersey, pp. 45-59 (1955).

10. NRC (National Research Council), Risk Assessment in the Federal Government: Managing the Process. NASNRC Committee on the Institutional Means for Assessment of Risks to Public Health, National Academy Press, Washington, D.C. (1983).

11. NTSB (National Transportation Safety Board), Rail Rapid Transit Report, Washington, D.C. (1972-1981).

12. OSHA (Occupational Safety and Health Administration), Process Safety Management of Highly Hazardous Chemicals, Explosives and Blasting Agents, Federal Register 57, 36, 6356-6402 (1992).

13. Reason, J., "A System Approach to Organizational Error," Ergonomics, Vol. 38, No. 8, pp. 1708-1721 (1995).

14. San Francisco BART (Bay Area Rapid Transit District), Passenger Injuries Quarterly Report, Oakland Center, CA(1985-1988).

15. Wang, L.C., "A Study of Rail Rapid Transit Hazards," Proceedings of the 8th Annual Conference for the Chinese Institute of Transportation, Taipei, Taiwan, R.O.C. pp. 81-88 (1993). 